packs of cigarettes sold in 1984, the 1985 tobacco HIT would have been 68 cents per pack ( $\$ 23$ billion in direct costs per 34 billion packs sold). ${ }^{4}$ In 1988 , there were 27.7 billion gallons of alcohol sold for a 1989 alcohol HIT approximating $\$ 1.45$ per six-pack of beer. A 1990 HIT estimate would probably be higher considering rising medical care costs.

Similar taxes have been proposed or are in effect. Recently, Rep Fortney Stark (D, Calif) introduced in Congress legislation to tax the tobacco companies directly for the Medicaid and Medicare costs secondary to tobacco-related illnesses, as reported by L. Jones in American Medical News (1990:3). A national HIT may be more effective, though, by directly taxing the patientconsumer at each purchase. While both would reduce consumption, the HIT would also provide a strong educational message, ie, smoking and alcohol consumption contribute to health care costs.

The HIT could then provide funds for a universal access program for the underinsured, estimated by the recent Pepper Commission at $\$ 24$ to $\$ 70$ billion annually. ${ }^{5}$ Additional HIT funds could provide the $\$ 2.2$ billion needed to upgrade and expand the drug treatment system. ${ }^{6}$ The HIT could also support tobacco and alcohol disease-related research, programs to stop smoking, and primary prevention educational programs. By providing for the financial support of the underinsured, all tobacco- and alcohol-consuming patients would have access to medical care for possible future illnesses, a "pay as you go" philosophy.

Universal access for all Americans will cost billions of dollars in additional funds. Our continued lack of financial disincentives for these costly human behaviors and our inadequate funding of primary and secondary treatments may cost us even more. A national HIT would be a large tax increase to many and face strong opposition from tobacco and alcohol companies. However, our behaviors of smoking tobacco and drinking alcohol cost too many lives (and dollars).

Rudolph J. Mueller, MD Rush Medical College Chicago, Ill

1. Lundberg GD, Blendon RJ. A special JAMA theme issue on caring for the uninsured and the underinsured. JAMA. 1990;264:739.

2. Rice DP, Hodgson TA, Sinsheimer P, et al. The economic costs of the health effects of smoking, 1984. Milbank $Q$. $1986 ; 64: 489-647$

3. Centers for Disease Control. Alcohol related disease impact-Wiseonsin, 1988. MMWR. 1990;39:178-187.

pact-Wisconsin, 1988. MMWR. 1990;39:178-187.
4. Statistical Abstract of the United States, 1990. 110th ed. Washington, DC: US Bureau of the Census; 1990.

5. Rockefeller JO. The Pepper Commission report on comprehensive health care. $N$ Engl J Med. 1990;323:1005-1007. 6. Gerstein DR, Lewin LS. Treating drug problems. N Engl J Med. 1990;323:844-848.

\section{Tobacco Coupons and Teenagers}

To the Editor-Despite mounting scientific evidence suggesting a causal relationship between tobacco advertising and increased consumption of tobacco products, particularly among adolescents, ${ }^{1-3}$ promotion of tobacco products by tobacco manufacturers continues to increase. ${ }^{4.5}$ The distribution of coupons redeemable for free tobacco products is a major focus for tobacco industry advertising. In $1988, \$ 876$ million of the $\$ 3$ billion spent by US tobacco manufacturers on tobacco advertising was spent on free coupon promotions. ${ }^{4}$ This study addresses the effects of tobacco coupon promotions on adolescents' ability to obtain tobacco products.

Study.-Two male and two female adolescent volunteers (aged 14 and 20 years and 15 and 19 years, respectively) were given either seven or eight coupons for the discounted purchase of cigarettes. These coupons had been promoted nationally by various tobacco manufacturers and obtained from local newspapers. The coupons stated that the cigarette discount was restricted to "smokers 21 years of age or older." Georgia state law prohibits the sale of tobacco products to anyone younger than 17 years. Each volunteer visited seven to eight different retail establishments, including supermarkets, pharmacies, and convenience stores. At each store, the volunteer attempted to redeem a cigarette coupon at the checkout counter. If the clerk began to ring up the purchase, the purchase attempt was deemed successful. If the clerk refused to make a sale or accept the coupon, the attempt was deemed a failure. No cigarette purchases were actually completed.

The adolescent volunteers attempted a total of 30 tobacco coupon redemptions. The 19- and 20-year-old subjects were successful in $100 \%$ (15/15) of their purchase attempts. The 14- and 15year-old subjects were successful $66 \%$ $(10 / 15)$ of the time $\left(\chi^{2}=6 ; P<.025\right)$. Successful redemption attempts occurred in four of four pharmacies, in eight of nine supermarkets, and in nine of 17 convenience stores. When the 14- or 15-year-old subjects were refused tobacco coupon redemption, the merchants stated that state law forbids the sale of tobacco to minors. In no instance was the volunteer's age questioned in reference to the tobacco manufacturer's stated criteria that coupon users must be at least 21 years of age.

Comment.-Tobacco coupon redemption programs are intended to promote increased tobacco consumption ei- ther through reductions in pack cost or by offering two or more packs for a lowered price. Adolescents in particular are thought to be most responsive to changes in cigarette costs; increases or decreases in the price of cigarettes limit or encourage smoking, respectively. ${ }^{6}$ This price elasticity of demand for cigarettes among adolescents is larger than that for adults. ${ }^{7}$ Our findings suggest that tobacco coupon redemption promotions may encourage adolescent smoking.

Adolescents have relatively easy access to discounts on tobacco products through the use of tobacco promotional coupons. While most states have laws limiting access to tobacco by minors, enforcement is often poor or nonexistent. ${ }^{8}$ Encouraging more stringent access laws and better enforcement of them is necessary. ${ }^{9}$ In addition, free tobacco coupon use should be limited to those aged 21 years or older. However, most states allow 18-year-old persons to purchase tobacco, and such adolescents were successful in $100 \%$ of their coupon purchase attempts in our study. Therefore, banning the distribution and use of tobacco coupons may be the most effective way to prevent underage adolescents from gaining access to discounted tobacco products.

Adam O. Goldstein, MD

Jonathan D. Klein, MD, MPH

University of North Carolina Chapel Hill

John W. Richards, Jr, MD

Paul M. Fischer, MD

Medical College of Georgia Augusta

1. Public Health Service. Reducing the Health Consequences of Smoking: 25 Years of Progress: A Report of the Surgeon General. Washington, DC: Office on Smoking and Health; 1989. US Dept of Health and Human Services publication 89-8411.

2. Goldstein AO, Fischer PM, Richards JW, Creten D. Relationship between high school student smoking and recognition of cigarette advertisements. J Pediatrics. 1987; 110:488-491.

3. Tye JB, Warner KE, Glantz SA. Tobacco advertising and consumption: evidence of a causal relationship. World Smoking Health. Winter 1988:8-13.

4. Davis RM. Current trends in cigarette advertising and marketing. N Engl J Med. 1987;316:725-732.

5. Centers for Disease Control. Cigarette advertisingUnited States, 1988. JAMA. 1990;263:2872-2875.

6. Warner KE. Smoking and health implications of a change in the federal cigarette excise tax. JAMA. 1986;255:10281032.

7. Lewit EM, Coate D. The potential for using excise taxes to reduce smoking. $J$ Health Econ. 1982;1:121-145.

8. Centers for Disease Control. State laws restricting mi8. Centers for Disease Control. State laws restriction
nor's access to tobacco. $M M W R$. 1990;39:349-353. 9. Difranza JR, Norwood BD, Garner DW, Tye JB. Legis lative efforts to protect children from tobacco. JAMA. $1987 ; 257: 3387-3389$

\section{Psychiatric Problems in Obese Children Followed up for 10 Years}

To the Editor. - The report by Epstein et al," "Ten-Year Follow-up of Behavioral, Family-Based Treatment for Obese Children," notes long-term positive results with that mode of treatment applied to 76 selected patients: obese 